\title{
The Impact of Coronavirus Pandemic on Stock Market Return: The Case of the MENA Region
}

\author{
Amr Arafa $^{1} \&$ Nader Alber ${ }^{2}$ \\ ${ }^{1}$ Ph.D. Holder, Faculty of Business, Ain Shams University, Cairo, Egypt \\ ${ }^{2}$ Professor of Finance, Faculty of Business, Ain Shams University, Cairo, Egypt \\ Correspondence: Nader Alber, Ain Shams University, Cairo, Egypt. E-mail: naderalberfanous@yahoo.com
}

Received: October 13, 2020

Accepted: November 5, 2020

Online Published: November 25, 2020

doi:10.5539/ijef.v12n12p100

URL: https://doi.org/10.5539/ijef.v12n12p100

\begin{abstract}
This paper attempts to investigate the impact of Coronavirus spread on the stock markets of MENA region. Coronavirus has been measured by cumulative total cases, cumulative total deaths, new cases and new deaths, while stock market return is measured by $\Delta$ in the stock market index. This has been applied on stock markets of 7 countries (Egypt, Jordan, Morocco, Qatar, Saudi Arabia, United Arab Emirates, and Tunisia), on daily basis during the period from March 1, 2020, to July 24, 2020.

Results indicate that stock market returns in the MENA countries tend to be negatively affected Coronavirus cumulative deaths and Coronavirus new deaths. A robustness check has been conducted for each country during the whole period, showing significant effect of Coronavirus cumulative cases in Jordan and Tunisia and significant effect of Coronavirus cumulative deaths in Jordan, Morocco and Tunisia, without any evidence about the effects of Coronavirus new cases and Coronavirus new cases.

After splitting the research period into 4 sub-periods (March, April, May, June- July 24), results support the impact of "cumulative Coronavirus cases" on stock market return in Jordan during May and in Morocco during April. Besides, the impact of "cumulative Coronavirus deaths" has been supported in in Morocco during April, and in Tunisia during March and June-July. Moreover, "new Coronavirus cases" seems to have a significant impact in Jordan during May and in Tunisia during March. Also, "new Coronavirus deaths" shows a significant effect in Morocco during May.
\end{abstract}

Keywords: Coronavirus, MENA region, stock market return

\section{Introduction}

The economic and social impact of Covid-19 pandemic has been substantial and has captured the attention of all investors. As a health crisis has mutated into a financial crisis, retail investors have suffered substantial losses (Zhang, Hu, \& Ji, 2020). According to (Baker, Bloom, Davis, Kost, Sammon, \& Viratyosin, 2020), the level of market volatility reached virtually unprecedented heights. As the number of confirmed cases has grown, markets have witnessed a significant decline in liquidity and value, with a response greater than that to any other public health emergency in at least the prior decade (Baig, Butt, Haroon, \& Rizvi, 2020).

The high-speed spread of the virus and the absence of a vaccine makes a difficult pressure on the governments monetary in providing the immediate fund for the important sector's likelihood of health and some important logistics. Besides, different economic sectors have been affected negatively due to Coronavirus spread and consequently, stock markets have been affected. These effects differ among regions and during time from the beginning of the pandemic.

Many scholars address the global stock markets reaction to Coronavirus spread and many studies focus on the most infected countries with a little attention concern about emerging markets or less-infected countries. This is why, we try to investigate the impact of Coronavirus pandemic on stock markets in the MENA countries.

The main question of this paper can be addressed as follows: Does Coronavirus spread have a significant impact on the stock market returns of MENA region? The research questions could be addressed as follows:

1) Do Coronavirus total cases affect stock market returns of MENA region?

2) Do Coronavirus total deaths affect stock market returns of MENA region? 
3) Do Coronavirus new cases affect stock market returns of MENA region?

4) Do Coronavirus new deaths affect stock market returns of MENA region?

After this introduction, section 2 discussed the related literature, while section 3 is for measuring variables and developing hypotheses. Section 4 illustrates the descriptive and diagnostic statistics and section 5 presents the hypotheses' testing while section 6 addresses the concluded remarks.

\section{Literature Review}

Many scholars concern with Coronavirus pandemic in terms of its drivers and spillovers. Magazzino, Mele \& Schneider (2020) and, Mele and Magazzino (2020) focuses on its relationship with pollution. Magazzino, Mele, and Schneider (2020) investigate the relationship between the Coronavirus spread and air pollution. Using Artificial Neural Networks (ANNs) experiments, results indicate that pre-determined particulate concentration can foster COVID-19 and make the respiratory system more susceptible to this infection. Besides, Mele and Magazzino (2020) explores the relationship between pollution emissions, economic growth, and COVID-19 deaths in India from January 29 to May 18, 2020 in 25 major Indian cities. Results indicate that a predetermined pollution concentration, caused by economic growth, could foster COVID-19 by making the respiratory system more susceptible to infection.

Other studies try to investigate the industry effect in terms of Coronavirus spread, where they split industries into winners and losers (e.g. Mazur, Dang, and Vega (2020) in the US stock market, Yan, Stuart, Tu, and Zhang (2020) in China and Kandil Goker, Eren, and Karaca (2020) in Turkey). Besides, many scholars concern with investigating and predicting the behavior of stocks' prices and trading volumes as well as market indexes. For example; Kumar (2006) concerns with S\&P CNX NIFTY Market Index and Sabri (2008) analyzes Arab stock markets.

Kumar (2006) aims at predicting the stock index by using the financial instruments price and attempt to predict the direction of S\&P CNX NIFTY Market Index of the National Stock Exchange. Linear discriminant analysis, logit artificial neural network, random forest and SVM are predicting models of the stock market direction. Results suggest that the SVM outperforms the other models of predicting the direction of the stock market movement. Besides, Sabri (2008) examines the price movement to determine the impact of trade volume on the volatility change in the stock price, covering eight Arab stock markets. Results indicate that there is an increase in trading volume and stock price volatility and that there are significant correlations between volumes and prices in the oil Arab states stock markets.

Stock market reaction to announcement about Coronavirus spread has been addressed by many papers during 2020, where this has been conducted by Alber (2020a) in the European stock markets, Alber (2020b) regarding the worst 6 countries (according to number of cumulative cases), Peterson and Ozili (2020) in major stock market indices, Alber and Saleh (2020) in stock markets of GCC countries and Smales (2020) in US Stock sectors.

Alber (2020a) attempts to investigate the effects of Coronavirus spread on the European stock markets. This has been applied on stock markets of Belgium, France, Germany, Italy, Netherlands Spain and UK, on daily basis during the period from Febreuary15, 2020 till May 24, 2020. Results have NOT supported these anticipated effects using panel analysis according to GMM technique, for the whole research period. After splitting the research period into 7 sub-periods (2-weeks each), results indicate that abnormal return of stock market seems to be sensitive to Coronavirus cases more than deaths, and to Coronavirus cumulative indicators more than new ones.

Alber (2020b) attempts to investigate the effects of Coronavirus spread on stock markets. Coronavirus spread has been measured by cumulative cases, new cases, cumulative deaths and new deaths. This has been applied on the worst 6 countries (according to number of cumulative cases), on daily basis over the period from March 1, 2020 till April 10, 2020. Results indicate that stock market return seems to be sensitive to Coronavirus cases more than deaths, and to Coronavirus cumulative indicators more than new ones. Besides, Peterson and Ozili (2020) examines the impact of social distance and policies on economic activities and stock market indices. Results indicate that lockdown days, monetary policy decisions, and international travel restrictions have been affected on economic activities and the closing, opening, lowest, and highest stock price of major stock market indices.

Alber and Saleh (2020) attempts to investigate the effects of 2020 Covid-19 world-wide spread on stock markets of GCC countries. Findings show that there are significant differences among stock market indices during the research period. Besides, stock market returns seem to be sensitive to Coronavirus new deaths. Moreover, this 
has been confirmed for March without any evidence about these effects during April and May 2020. Moreover, Smales (2020) addresses the investor attention and the response of US Stock sectors to the COVID-19 crisis from Dec., 31, 2019 to May, 31, 2020. This has been conducted using the S\&P500 Composite Index and considering returns on the 11 sectors within the Global Industry Classification Standard (GICS).

Recently, Alber and Dabour (2020) investigates the opportunities of growth under restrictions of social distancing for FinTech. This has been conducted on 10 countries (United States, United Kingdom, Egypt, United Arab Emirates, Saudi Arabia, Japan, South Korea, Italy, India and Nigeria) during the period from March to June 2020. Results indicate that social distancing may affect digital payments. This has been supported for retail and recreation, grocery and pharmacy, transit stations and workplaces, without any evidence about significant effects for parks and residentials.

Comparing with literature, it's important to pinpoint that it considers not only both of infection and death indicators, but also, both of cumulative and new ones. Besides, Coronavirus spread has been measured relatively, where all measures are adjusted per million of country population.

\section{Measuring Variables and Developing Hypotheses}

The independent variables have been measured by "cumulative Coronavirus cases", "cumulative Coronavirus deaths", "Coronavirus new cases", "Coronavirus new deaths", while the dependent variables have been measured by daily stock markets returns of the MENA countries included in this study. Data are obtained from stock markets of Egypt, Jordan, Morocco, Qatar, Saudi Arabia, and the United Arab Emirates, on daily basis during the period from March 1, 2020, to July 24, 2020. Table 1 illustrates the research variables, as follows:

Table 1. Research variables

\begin{tabular}{lll}
\hline Variable & Calculation & \\
\hline Stock market return * & Daily $\Delta$ in stock markets return & $\Delta$ CINP \\
Cumulative Coronavirus cases $* *$ & Cumulative Coronavirus cases (per mn of population) & TOCA \\
Cumulative Coronavirus deaths $* *$ & Cumulative Coronavirus deaths (per mn of population) & TODTH \\
New Coronavirus cases $* *$ & New Coronavirus cases (per mn of population) & NCA \\
New Coronavirus deaths $* *$ & New Coronavirus deaths (per million of population) & NDTH \\
\hline
\end{tabular}

*Data collected from: https://www.investing.com/ indices/

**Data collected from: https://ourworldindata.org/coronavirus-source-data.

Table 2 illustrates the stock indices used to estimate the dependent variables, as follows:

Table 2. Research sample

\begin{tabular}{llc}
\hline Country & Stock index & No. of listed stocks \\
\hline Egypt & EGX 30 (EGX30) & 30 \\
Jordan & Amman SE General (AMGNRLX) & 97 \\
Morocco & Moroccan All Shares (MASI) & 73 \\
Qatar & QE All Shares (QEAS) & 46 \\
Saudi Arabia & Tadawul All Share (TASI) & 200 \\
United Arab Emirates & ADX General (ADI) & 65 \\
Tunisia & Tunindex (TUNINDEX) & 80 \\
\hline
\end{tabular}

Source: https://www.investing.com/ indices/.

This paper aims at testing the significance of the Coronavirus spread on the stock market return of the MENA region. This has been conducted by testing the following hypotheses:

1) There is no significant impact of the Coronavirus cumulative total cases on the stock market return of the MENA region.

2) There is no significant impact of the Coronavirus cumulative total deaths on the on the stock market return of the MENA region.

3) There is no significant impact of the Coronavirus new cases on the on the stock market return of the MENA region.

4) There is no significant impact of the Coronavirus new deaths on the on the stock market return of the 


\section{MENA region.}

This means that null hypothesis $\mathrm{Ha}: \beta=0$ and the alternative hypothesis $\mathrm{Hb}: \beta \# 0$, where $\beta$ is the regression coefficient as the following functions:

$$
\begin{aligned}
& \boldsymbol{\Delta}_{-} \mathrm{CINP}=\alpha+\beta_{1} \text { TOCA } \\
& \boldsymbol{\Delta}_{-} \mathrm{CINP}=\alpha+\beta_{2} \text { TODTH } \\
& \boldsymbol{\Delta}_{-} \mathrm{CINP}=\alpha+\beta_{3} \mathrm{NCA} \\
& \boldsymbol{\Delta}_{-} \mathrm{CINP}=\alpha+\beta_{4} \mathrm{NDTH}
\end{aligned}
$$

We have tested the effect of each independent variable separately, due to the correlation among these variables, to avoid the problem of multicollinearity, as shown in table 3 .

\section{Descriptive and Diagnostic Statistics}

\begin{tabular}{|c|c|c|c|c|c|c|c|}
\hline period & variables & $\Delta \_$CINP & TOCA & TODTH & $\mathrm{NCA}$ & NDTH & \\
\hline & $\Delta \_$CINP & 1 & & & & & \\
\hline The & TOCA & 0.04278 & 1 & & & & \\
\hline Whole & TODTH & 0.058722 & 0.59973 & 1 & & & \\
\hline \multirow[t]{2}{*}{ Period } & NCA & 0.056503 & 0.69607 & 0.310245 & 1 & & \\
\hline & NDTH & 0.062156 & 0.444378 & 0.70172 & 0.378914 & 1 & 1 \\
\hline \multirow[t]{2}{*}{ Period 1} & $\Delta \_$CINP & 1 & & & & & \\
\hline & TOCA & 0.04278 & 1 & & & & \\
\hline 01-Mar & TODTH & 0.058722 & 0.59973 & 1 & & & \\
\hline \multirow[t]{2}{*}{ 31-Mar } & $\mathrm{NCA}$ & 0.056503 & 0.69607 & 0.310245 & 1 & & \\
\hline & NDTH & $6.22 \mathrm{E}-02$ & 0.444378 & 0.70172 & 0.378914 & & 1 \\
\hline \multirow[t]{2}{*}{ Period 2} & $\Delta \_$CINP & 1 & & & & & \\
\hline & TOCA & 0.028857 & 1 & & & & \\
\hline 01-Apr & TODTH & 0.009403 & 0.298918 & 1 & & & \\
\hline \multirow[t]{2}{*}{ 30-Apr } & $\mathrm{NCA}$ & 0.02493 & 0.953167 & 0.18262 & 1 & & \\
\hline & NDTH & -0.03283 & 0.059391 & 0.511608 & 0.016995 & & 1 \\
\hline \multirow[t]{2}{*}{ Period 3} & $\Delta \_$CINP & 1 & & & & & \\
\hline & TOCA & 0.012797 & 1 & & & & \\
\hline 01-May & TODTH & 0.042874 & 0.155582 & 1 & & & \\
\hline & NCA & -0.01084 & 0.986839 & 0.076209 & 1 & & \\
\hline & NDTH & 0.017898 & 0.047996 & 0.655844 & 0.013419 & & 1 \\
\hline \multirow[t]{2}{*}{ Period 4} & $\Delta \_$CINP & 1 & & & & & \\
\hline & TOCA & 0.034923 & 1 & & & & \\
\hline 01-Jun & TODTH & -0.01284 & 0.532713 & 1 & & & \\
\hline \multirow[t]{2}{*}{ 24-Jul } & NCA & 0.083431 & 0.755768 & 0.317873 & 1 & & \\
\hline & NDTH & 0.040494 & 0.394689 & 0.654639 & 0.471489 & & 1 \\
\hline
\end{tabular}

Table 3 shows the correlation between the independent variables, for the whole research period and for the sub-periods, as follows:

Table 3. Correlation coefficients between independent variables

Source: outputs of data processing using Eviews10.

Table 3 shows that correlation coefficients between independent variables are high to the extent that doesn't allow to investigate their effect in only one model due to the multicollinearity problem and this is why we have investigated their effects separately.

Tables 4 illustrates the descriptive statistics variables for the research variables, as follows: 
Table 4. Descriptive statistics

\begin{tabular}{lccccc}
\hline Variables & $\Delta \_$CINP & TOCA & TODTH & NCA & NDTH \\
\hline Mean & -0.000981 & 2874.121 & 10.38227 & 50.76790 & 0.221916 \\
Median & 0.000000 & 131.7640 & 4.061000 & 3.818000 & 0.054000 \\
Maximum & 0.084100 & 37441.43 & 74.71200 & 817.4070 & 1.735000 \\
Minimum & -0.095100 & 0.000000 & 0.000000 & 0.000000 & 0.000000 \\
Std. Dev. & 0.019283 & 7440.208 & 15.28585 & 114.6369 & 0.368830 \\
Skewness & -0.887034 & 3.476948 & 1.905994 & 3.456699 & 2.059389 \\
Kurtosis & 9.085510 & 14.34336 & 6.093011 & 15.68349 & 6.589041 \\
Jarque-Bera & 1109.993 & 4890.414 & 665.7063 & 5764.398 & 824.4832 \\
Probability & 0.000000 & 0.000000 & 0.000000 & 0.000000 & 0.000000 \\
Observations & 663 & 663 & 663 & 663 & 663 \\
\hline
\end{tabular}

Source outputs of data processing using Eviews10.

Regarding normality, Jarque-Bera values indicate that independent variables are normally distributed at a P-value of 0.00 .

\section{Testing Hypotheses}

This paper aims at testing the significance of the Coronavirus spread on the stock market return of the MENA region. Using panel data analysis according to LS method, results indicate that Coronavirus deaths may have significant effects on stock markets' returns, while Coronavirus cases don't seem to have any significant effects. So, for the second and fourth hypotheses, we can reject the null hypothesis and accept the alternative one. A robustness check has been conducted by splitting the research period into 4 periods, as shown from tables from (5) to (8), as follows:

Table 5. Effects of Coronavirus cumulative cases on market return of MENA region

\begin{tabular}{lccccc}
\hline \multicolumn{1}{c}{ Item } & period (1) & period (2) & period (3) & period (4) & all period \\
\hline$\alpha$ & -0.0095 & 0.0022 & 0.00037 & 0.00046 & -0.00129 \\
& $(0.0022)^{* * *}$ & $(0.1966)$ & $(0.7759)$ & $(0.4093)$ & $(0.106)^{*}$ \\
$\beta_{1}$ (all countries) & 5.93100 & 5.82001 & 4.78001 & 2.6700 & 1.1100 \\
& $(0.2875)$ & $(0.7464)$ & $(0.8906)$ & $(0.5661)$ & $(0.2713)$ \\
$\beta_{1}$ (Jordan) & - & - & 0.0010 & - & 6.3051 \\
& & & $(0.0001)^{* * *}$ & & $(0.0191)^{* * *}$ \\
$\beta_{1}$ (Morocco) & - & 0.00016 & - & - & - \\
$\beta_{1}$ (Tunisia) & - & $(0.0103)^{* * *}$ & & - & 6.74200 \\
R-squared & & - & - & $-0.0032)^{* * *}$ \\
Durbin-Watson stat & 0.0079 & 0.00083 & 0.0002 & 0.012 & 0.00183 \\
Obs. & 1.8742 & 1.742 & 1.515 & 1.661 & 1.7266 \\
\hline
\end{tabular}

Source outputs of data processing using Eviews 10.

Table 6. Effects of Coronavirus cumulative deaths on market return of MENA region

\begin{tabular}{lccccc}
\hline \multicolumn{1}{c}{ Item } & period (1) & period (2) & period (3) & period (4) & Whole period \\
\hline$\alpha$ & -0.0102 & 0.0022 & -0.0001 & 0.0007 & -0.00175 \\
& $(0.0012)^{* * *}$ & $(0.437)$ & $(0.9297)$ & $(0.315)$ & $(0.0535)$ \\
$\beta_{2}$ (all countries) & 0.0260 & 9.5362 & 8.7070 & -5.3551 & 7.4131 \\
& $(0.1439)^{*}$ & $(0.9161)$ & $(0.6448)$ & $(0.833)$ & $(0.1309)^{*}$ \\
$\beta_{2}$ (Jordan) & & & & 0.0076 \\
& - & - & & - & $(0.011)^{* * *}$ \\
$\beta_{2}$ (Morocco) & - & 0.00518 & - & - & 0.001877 \\
$\beta_{2}$ (Tunisia) & 0.0323 & $(0.0100) * * *$ & & -0.032 & $(0.0080)^{* * *}$ \\
R-squared & $(0.0300)^{* * *}$ & - & - & $(0.0004) * * *$ & $(0.00165$ \\
Durbin-Watson stat & 0.0148 & 0.0012 & 0.00183 & 0.00016 & $0.001)^{* * *}$ \\
Obs. & 1.894 & 1.742 & 1.515 & 1.659 & 1.729 \\
\hline
\end{tabular}

Source outputs of data processing using Eviews10. 
Table 7. Effects of Coronavirus new cases on market return of MENA region

\begin{tabular}{lccccc}
\hline \multicolumn{1}{c}{ Item } & period (1) & period (2) & period (3) & period (4) & Whole period \\
\hline$\alpha$ & -0.008 & 0.0022 & 0.0005 & 0.0002 & -0.0014 \\
& $(0.0069)^{* * *}$ & $(0.1904)$ & $(0.6825)$ & $(0.637)$ & $(0.074)$ \\
$\beta_{3}$ (all countries) & -9.3343 & 6.6321 & -8.67253 & 5.1111 & 9.5741 \\
& $(0.802)$ & $(0.78101)$ & $(0.090)$ & $(0.1701)$ & $(0.1461)$ \\
$\beta_{3}$ (Jordan) & - & - & $(0.0074)$ & - & - \\
& & & $(0.028)^{* * *}$ & & - \\
$\beta_{3}$ (Tunisia) & 0.0046 & - & - & - & 0.00031 \\
R-squared & $(0.0490)^{* *}$ & 0.0006 & 0.0001 & 0.00069 & 1.731 \\
Durbin-Watson stat & 0.0004 & 1.745 & 1.51 & 1.667 & 663 \\
Obs. & 1.847 & 128 & 118 & 272 & \\
\hline
\end{tabular}

Source outputs of data processing using Eviews10.

Table 8. Effects of Coronavirus New Death on $\Delta$ index value of MENA region

\begin{tabular}{|c|c|c|c|c|c|}
\hline item & period (1) & period (2) & period (3) & period (4) & Whole period \\
\hline \multirow{2}{*}{$\alpha$} & -0.0085 & 0.0029 & 0.0003 & 0.0003 & -0.0017 \\
\hline & $(0.0048)^{* * *}$ & $(0.1400)^{*}$ & $(0.8181)$ & $(0.5610)$ & $(0.0511)$ \\
\hline \multirow{2}{*}{$\beta_{4} \quad$ (all countries) } & 0.0167 & -0.0032 & 0.0008 & 0.0006 & 0.0003 \\
\hline & $(0.7710)$ & $(0.7121)$ & $(0.8471)$ & $(0.5060)^{* *}$ & $(0.109)^{*}$ \\
\hline \multirow{2}{*}{$\beta_{4}($ Morocco $)$} & & & 0.15236 & & \\
\hline & - & - & $(0.023) * * *$ & - & - \\
\hline R-squared & 0.00059 & 0.001 & 0.00032 & 0.00164 & 0.0038 \\
\hline Durbin-Watson stat & 1.865 & 1.728 & 1.511 & 1.656 & 1.7311 \\
\hline Obs. & 145 & 128 & 118 & 272 & 663 \\
\hline
\end{tabular}

Source outputs of data processing using Eviews 10.

A robustness check has been conducted for each country during the whole period, showing significant effect of Coronavirus cumulative cases in Jordan and Tunisia and significant effect of Coronavirus cumulative deaths in Jordan, Morocco and Tunisia, without any evidence about the effects of Coronavirus new cases and Coronavirus new cases. So, for the first and second hypotheses, we can reject the null hypothesis and accept the alternative one.

Another robustness check has been conducted for each country during each period, showing the following:

1) There's a significant impacts of Coronavirus cumulative cases in Jordan during May and the whole period, in Morocco during April and in Tunisia during the whole period.

2) There's a significant impacts of Coronavirus cumulative cases in all countries during March and the whole period, in Jordan during the whole period, in Morocco during April and the whole period and in Tunisia during March, June-July and the whole period.

3) There's a significant impacts of Coronavirus new cases in Jordan during and in Tunisia during March.

4) There's a significant impacts of Coronavirus new deaths in all countries during June-July and for the whole period, and in Morocco during May.

\section{Summary and Concluded Remarks}

This paper attempts to investigate the impact of Coronavirus spread on the stock markets of MENA region. Coronavirus has been measured by cumulative total cases, cumulative total death, new cases and new deaths, while stock market return is measured by $\Delta$ in the stock market index. This has been applied on stock markets of 7 countries (Egypt, Jordan, Morocco, Qatar, Saudi Arabia, United Arab Emirates, and Tunisia), on daily basis during the period from March 1, 2020, to July 24, 2020.

Results indicate that stock market returns in the MENA countries tend to be negatively affected Coronavirus cumulative deaths and Coronavirus new deaths. A robustness check has been conducted for each country during the whole period, showing significant effect of Coronavirus cumulative cases in Jordan and Tunisia and significant effect of Coronavirus cumulative deaths in Jordan, Morocco and Tunisia, without any evidence about the effects of Coronavirus new cases and Coronavirus new cases.

After splitting the research period into 4 sub-periods (March, April, May, June- July 24), results support the 
impact of "Cumulative Coronavirus Cases" on stock market return in Jordan during May and in Morocco during April. Besides, the impact of "Cumulative Coronavirus Deaths" has been supported in in Morocco during April, and in Tunisia during March and June-July. Moreover, "Coronavirus New Cases" seems to have significant impact in Jordan during May and in Tunisia during March. Also, "Coronavirus New Deaths" shows a significant effect in Morocco during May.

\section{References}

Alber, N. (2020a). Finance in the time of Coronavirus during 100 Days of Isolation, The Case of the European Stock Markets. https://doi.org/10.2139/ssrn.3631517

Alber, N. (2020b). The Effect of Coronavirus Spread on Stock Markets,The Case of the Worst 6 Countries. https://doi.org/10.2139/ssrn.3578080

Alber, N., \& Dabour, M. (2020). The Dynamic Relationship between FinTech and Social Distancing under COVID-19 Pandemic: Digital Payments Evidence. International Journal of Economics and Finance, 12(11). https://doi.org/10.5539/ijef.v12n11p109

Alber, N., \& Saleh, A. (2020). The Impact of Covid-19 Spread on Stock Markets: The Case of the GCC Countries. International Business Research, 13(11). https://doi.org/10.5539/ibr.v13n11p16

Baig, A., Butt, H., Haroon, O., \& Rizvi, S. (2020). Deaths, Panic, Lockdowns and US Equity Markets: The Case of COVID-19 Pandemic. https://doi.org/10.2139/ssrn.3584947

Baker, S., Bloom, N., Davis, S., Kost, K., Sammon, M., \& Viratyosin, T. (2020). The Unprecedented Stock Market Reaction to COVID-19. Working Paper. https://doi.org/10.35188/UNU-WIDER/2020/896-2

Kandil, G. I., Eren, B., \& Karaca, S. (2020). The Impact of the COVID-19 (Coronavirus) on the Borsa Istanbul Sector Index Returns: An Event Study. Gaziantep University Journal of Social Sciences, Special Issue, 14-41.

Koijen, N. (2020). Coronavirus: Impact on Stock Prices and Growth Expectations. Retrieved from https://papers.ssrn.com/sol3/papers.cfm?abstract_id=3555917.

Kumar, M. (2006). Forecasting Stock Index Movement: A Comparison of Support Vector Machines and Random Forest. https://doi.org/10.2139/ssrn.876544

Liu, H., Manzoor, A., Wang, C., Zhang, L., \& Manzoor, Z. (2020). The COVID-19 Outbreak and Affected Countries Stock Markets Response. International Journal of Environmental Research and Public Health, 17(8), 1-19. https://doi.org/10.3390/ijerph17082800

Magazzino, C., Mele, M., \& Schneider, N. (2020). The relationship between air pollution and COVID-19-related deaths: An application to three French cities. Applied Energy, 279, 115835. https://doi.org/10.1016/j.apenergy.2020.115835

Mazur, M., Dang, M., \& Vega, M. (2020). COVID-19 and March 2020 Stock Market Crash. Evidence from $S \& P 1500$. https://doi.org/10.2139/ssrn.3586603

Mele, M., \& Magazzino, C. (2020). Pollution, Economic Growth, and COVID-19 Deaths in India: A Machine Learning Evidence. Environmental Science and Pollution Research. https://doi.org/10.1007/s11356-020-10689-0

Peterson, K., \& Ozili, T. (2020). Spillover of COVID-19: Impact on the Global Economy. Retrieved from https://papers.ssrn.com/sol3/papers.cfm?abstract_id=3562570

Sabri, N. (2008). The Impact of Trading Volume on Stock Price Volatility in the Arab Economy. https://doi.org/10.2139/ssrn.1097624

Smales, L. (2020). Investor Attention and the Response of US Stock Sectors to the COVID-19 Crisis. https://doi.org/10.2139/ssrn.3625487

Zhang, D., Hu, M., \& Ji, Q. (2020). Financial Markets under the Global Pandemic of COVID-19. Finance Research Letters, In Press. https://doi.org/10.1016/j.frl.2020.101528

\section{Copyrights}

Copyright for this article is retained by the author(s), with first publication rights granted to the journal.

This is an open-access article distributed under the terms and conditions of the Creative Commons Attribution license (http://creativecommons.org/licenses/by/4.0/). 